\title{
Intrauterine Growth Retardation: Altered Hepatic Energy and Redox States in the Fetal Rat
}

\author{
EDWARD S. OGATA, SARAH L. SWANSON, JAMES W. COLLINS, JR., AND SANDRA L. FINLEY \\ Departments of Pediatrics, Obstetrics and Gynecology, Northwestern University Medical School, Division of \\ Neonatology Children's Memorial Hospital and Prentice Women's Hospital, Chicago, Illinois 60614
}

\begin{abstract}
We determined the extent to which ligating both maternal uterine arteries affects fetal hepatic energy and redox states in the fetal rat. Bilateral maternal uterine artery ligation on $\mathbf{d} 18$ of the rat's 21.5-d gestation significantly inhibits fetal growth; sham surgery limits growth to a lesser extent. Within $12 \mathrm{~h}$ of surgery and persisting to d 19, small-for-gestational age (SGA) fetuses had significantly diminished ATP/ADP and adenylate charge ratios, whereas sham fetuses had values intermediate between SGA and normal. Hepatic mitochondrial redox state demonstrated similar changes. Cytosolic redox state in SGA fetuses at 12 and $24 \mathrm{~h}$ after surgery was significantly elevated. SGA fetuses had significantly diminished plasma insulin and elevated glucagon concentrations. On d 19 and 20, hepatic ATP/ADP and cytosolic $\mathrm{NAD}^{+} / \mathrm{NADH}$ correlated directly for sham and normal but not SGA fetuses. Alterations in glucose, insulin, and glucagon availability and hypoxia were responsible for the changes in energy and redox states. They may also have disassociated hepatic cytosolic from mitochondrial redox states and altered the equilibrium between adenine and nicotinamide nucleotides. These altered cellular functions retarded fetal growth. Newborn SGA, sham, and normal rat pups had similar hepatic ATP/ADP, cytosolic, and mitochondrial redox states at 10 and $240 \mathrm{~min}$ after delivery suggesting that the hypoglycemia which developed in SGA pups was not attributable to alterations in these variables. (Pediatr Res 27: 56-63, 1990)
\end{abstract}

Abbreviations

AC, acetoacetate

SGA, small-for-gestational age

Intrauterine growth retardation is often ascribed to "uteroplacental insufficiency," a poorly defined clinical term suggesting compromised maternal-fetal relations (1). To determine the factors responsible for intrauterine growth retardation, we performed bilateral uterine artery ligation in the maternal rat. This technique, which can be considered an extreme example of "uteroplacental insufficiency," alters a number of physiologic variables including gaseous exchange and metabolic fuel availability. Alterations in these variables are known to affect fetal growth; however, the mechanisms by which this occurs are not completely understood. Particularly unclear is the impact of these alterations on cellular metabolic processes. For these reasons we

Received June 8, 1898; accepted August 29, 1989.

Correspondence Edward S. Ogata, M.D. Division of Neonatology Children's Memorial Hospital, 2300 Children's Plaza, Chicago, IL 60614.

Supported in part by the Juvenile Diabetes Foundation and NIH 1P01 19070. measured hepatic energy state as reflected by ATP/ADP relations and oxidation reduction ("redox") states as represented by cytosolic and mitochondrial $\mathrm{NAD}^{+} / \mathrm{NADH}$ ratios in the SGA fetal and neonatal rat. Both energy and redox states are critical regulators of intermediary metabolism and thereby directly affect cellular growth. In addition, both variables are involved in hepatic glucose production, and SGA neonates are at risk of developing hypoglycemia.

Our data indicate that bilateral maternal uterine artery ligation in the rat acutely decreases fetal hepatic ATP/ADP and mitochondrial $\mathrm{NAD}^{+} / \mathrm{NADH}$ relations but increases cytosolic $\mathrm{NAD}^{+} / \mathrm{NADH}$. These changes and alterations in other physiologic variables contributed to development of fetal growth retardation. During the neonatal period, ATP/ADP, adenylate charge ratio, and redox states increase appropriately in SGA newborn rat pups. Alterations in these variables are not directly responsible for the hypoglycemia that develops in the SGA newborn rat.

\section{MATERIALS AND METHODS}

Surgery. We have reported the details of our surgical techniques (2). In brief, on d 18 of their 21.5-d gestation, we assigned timed-gestation Sprague-Dawley rats (prepregnancy wt 170-190 g, Harlan Laboratories, Madison, WI) to one of three groups: 1) bilateral uterine artery ligation (SGA), 2) sham surgery (sham), or 3) no surgery (normal). We anesthetized rats undergoing surgery with chloral hydrate $(35 \mathrm{mg} / 100 \mathrm{~g}$ body wt), opened the peritoneal cavity, exposed the uterus, and ligated both uterine vessels with 4-0 silk suture. The procedure requires approximately $20 \mathrm{~min}$, and rats are awake within $2 \mathrm{~h}$ of initiation of anesthesia.

We used only rats who had eight to 14 fetuses because fetal growth is to a degree inversely related to litter size (3). As in earlier studies, we characterized the intrauterine growth of SGA, sham, and normal fetuses by determining wet and dry wt of carcasses (4).

We performed two types of fetal sampling studies. To obtain fetal liver for nucleotides, intermediary metabolites, and glycogen, we killed mothers by stunning and cervical dislocation, quickly removed fetuses by cesarean section, and decapitated them. We immediately removed their livers and froze them in liquid nitrogen. Inasmuch as a number of investigators participated in this process, all fetal livers were frozen within $15-20 \mathrm{~s}$ of the start of this procedure. From one or two fetuses of each litter, we obtained blood from cut axillary vessels to determine mixed arteriovenous $\mathrm{pH}$ and blood gas tensions. We performed this sampling at baseline, 12, 24 (d 19), 48 (d 20), and 72 (d 21) $\mathrm{h}$ after ligation or sham surgery. We also killed normal rats at baseline and at each of these times.

In the second series of studies we determined maternal-fetal glucose relations and fetal plasma hormone concentrations by 
sampling blood from fetuses in maternal rats with the fetalplacental circulation intact. We adopted this (5) technique from previous studies. At the above indicated times, we anesthetized a maternal rat with chloral hydrate, exposed the uterus, and incised it sequentially so that individual fetuses could be sequentially removed leaving their placentas attached to the uterine wall. We dried the fetuses and maintained them at $37^{\circ} \mathrm{C}$, applied minimal tension to the umbilical cord, and obtained blood from cut axillary vessels. We obtained maternal blood simultaneously from tail veins. For studies on d 18, we performed uterine artery ligation or sham surgery and allowed the mother to recover from surgery. We anesthetized the mothers once again at $12 \mathrm{~h}$ for fetal and maternal sampling.

For neonatal studies, we killed mothers by stunning and cervical dislocation on 21.5 , delivered pups by cesarean section, and maintained them in a temperature-humidity controlled environment as described previously (6). We randomly selected pups from one half of each litter for sampling at either 10 or 240 min. At these times we cut the pups' axillary vessels to obtain blood and then quickly decapitated them to allow removal and freezing of their livers. This technique allows sequential determination of metabolites in litter mates.

This protocol was approved by the Animal Care Committee of Northwestern University Medical School.

Metabolic determinations. We pulverized the frozen livers to a fine powder at the temperature of dry ice, extracted them with iced $\mathrm{HClO}_{4}$ and neutralized the supernatant with $30 \% \mathrm{KOH}$. We used enzymatic microassays to measure lactate (7), pyruvate (8), BOHB, AC (9), ATP, ADP, and AMP (10). We used the method of Williamson et al. (11) to calculate $\mathrm{NAD}^{+} / \mathrm{NADH}$ in cytosol and mitochondria. Determination of the cytosolic redox state uses the equilibrium reaction between pyruvate and lactate requiring lactate dehydrogenase. The cytosolic redox state is calculated from the reciprocal of the product of the equilibrium constant of lactate dehydrogenase and the ratio of pyruvate to lactate concentrations. Similarly, the redox state in mitochondria can be derived from the equilibrium equation for BOHB and $\mathrm{AC}$. These metabolites of fatty acid oxidation represent mitochondrial $\beta$-hydroxybutyrate dehydrogenase. The equilibrium constant for lactate dehydrogenase was $1.11 \times 10^{4}$ and for $\beta$ hydroxybutyrate dehydrogenase, $4.93 \times 10^{2}$ (11). These constants were validated in the original application of this methodology in the adult (11) and fetal (12) rat. The constants were determined under normal and abnormal conditions including hypoxia and starvation for the fetus.

The determination of hepatic adenine nucleotide concentrations allows determination of ATP/ADP and the hepatic adenylate charge ratio $[((\mathrm{ATP})+1 / 2(\mathrm{ADP})) /((\mathrm{ATP})+(\mathrm{ADP})+$ (AMP))] (12). The former approximates energy availability, whereas the latter expresses the equilibrium between adenine nucleotides mediated by adenylate kinase and is therefore a more quantitative measure of energy state.

The methods for determining the other metabolic fuels and hormones have been reported $(2,4,6)$. In brief, we measured plasma glucose concentrations with an automated glucose analyzer (Beckman II; Beckman Instruments Inc., Fullerton, CA) and glycogen concentrations with amyloglucosidase. We used double antibody RIA to measure plasma insulin and glucagon concentrations with rat insulin and porcine glucagon as standards. Arteriovenous blood gas tensions and $\mathrm{pH}$ were determined with an ILC 1301 automated blood gas analyzer.

Statistics. We used the Student's paired $t$ test to compare values in a series within a group and analysis of variance for comparison of values between groups. Analyses were performed with a Statistical Program for the Social Sciences on a Cyber 170-780 computer at the Vogelback Center of Northwestern University, Chicago, IL (13). Data are presented as the mean \pm SEM. Values for at least 25 fetuses and pups representing a minimum of six litters are represented for each measurement.

\section{RESULTS}

Growth. Maternal uterine artery ligation retarded intrauterine growth, whereas sham surgery had a significant although less profound effect. All fetuses of maternal uterine artery ligation and sham-operated mothers survived. Twenty-four $h$ after uterine artery or sham surgery, SGA and sham fetuses were significantly lighter than controls and had equivalent body wt (expressed as wet or dry wt). On d 20,21, and at birth, SGA fetuses were the lightest, sham fetuses intermediate, and normal fetuses the heaviest. (Birth wt SGA 4.16 $\pm 0.05 \mathrm{~g}$; sham $4.81 \pm 0.06 \mathrm{~g}$; normal $5.79 \pm 0.05 \mathrm{~g}, p<0.001)$. Figure 1 demonstrates that the growth rates of SGA and sham fetuses were diminished similarly between d 18 and 19 ; between d 19 and 20 sham fetuses increased their growth rate, whereas SGA fetuses continued to have significantly delayed growth. Hepatic growth paralleled body growth. Comparison of wet and dry wt indicated that water comprised 75 to $80 \%$ of body mass. This proportion was similar in all three groups.

Metabolic variables. Sham surgery and maternal uterine artery ligation significantly reduced fetal hepatic energy state. Twelve $h$ after maternal surgery, fetal hepatic ATP/ADP (Fig. 2) and adenylate charge ratios (Table 1) differed significantly among the three groups. Although 12-h ATP/ADP and adenylate charge ratios in normal fetuses were similar to baseline values on $\mathrm{d} 18$, values for SGA fetuses were the lowest, and for shams it was intermediate. These differences persisted into d 19; by d 20 and 21 , there were no differences between groups. Both decreases in ATP and increases in ADP were responsible for the differences in ATP/ADP and adenylate charge relations. AMP concentrations did not demonstrate a consistent pattern of difference between groups although two significant differences were noted (Table 1). At $12 \mathrm{~h}$ after ligation, SGA fetuses had significantly diminished mitochondrial $\mathrm{NAD}^{+} / \mathrm{NADH}$ (Fig. 3). Normal fetuses had values similar to baseline, whereas sham fetuses had intermediate values. These differences were also apparent on $\mathrm{d}$ 19. By d 20 and 21 , all groups had similar values. Significant changes in hepatic $\mathrm{BOHB}$ concentrations were responsible for the differences in mitochondrial NAD ${ }^{+} / \mathrm{NADH}$ (Table 2).

Fetal hepatic cytosolic $\mathrm{NAD}^{+} / \mathrm{NADH}$ demonstrated a different pattern. Twelve $h$ after ligation, SGA fetuses had significantly elevated cytosolic $\mathrm{NAD}^{+} / \mathrm{NADH}$; shams, intermediate values; and normals, values unchanged from baseline. These differences were also apparent on d 19. By d 20, SGA fetuses had even greater values, whereas sham fetuses had values similar to normal. Sham and normal fetuses increased values significantly between d 20 and $21(p<0.01)$ to attain SGA values (Fig. 4). Differences in pyruvate concentrations were responsible for the alterations in cytosolic $\mathrm{NAD}^{+} / \mathrm{NADH}$ as lactate concentrations did not differ significantly between groups (Table 2 ).

On d 19 (Fig. 5) and 20, hepatic ATP/ADP and cytosolic $\mathrm{NAD}^{+} / \mathrm{NADH}$ of sham and normal fetuses correlated directly (d $20, r=0.768, p<0.01)$. These variables did not correlate for SGA fetuses on either day. Similar relations were apparent for adenylate charge ratios (d 19,r=0.699, $p<0.01 ; \mathrm{d} 20, r=$ $0.712, p<0.01$ )

By $12 \mathrm{~h}$ after uterine artery ligation, hepatic glycogen concentrations were significantly diminished in SGA compared to sham and normal fetuses. On d 19, SGA fetuses had the lowest, shams intermediate, and normals the greatest concentrations $(p<0.01)$. On d 20 and 21 SGA fetuses continued to have significantly diminished concentrations, whereas sham and normal fetuses had equivalent values (Table 3 ).

On d 18, $12 \mathrm{~h}$ after uterine artery ligation, SGA fetuses had a mean arteriovenous $\mathrm{pH}$ of $7.08 \pm 0.007, \mathrm{PCO}_{2}$ of $89 \pm 6$ torr, and $\mathrm{PO}_{2}$ of $14 \pm 5$ torr, whereas sham fetuses had values of 7.16 $\pm 0.006, \mathrm{PCO}_{2}$ of $74 \pm 8$ torr, and $\mathrm{PO}_{2}$ of $21 \pm 6$ torr, and normal fetuses had a pH of $7.21 \pm 0.008, \mathrm{PCO}_{2}$ of $61 \pm 5$ torr, and $\mathrm{PO}_{2}$ of $26 \pm 3$ torr. All of these variables were significantly different 


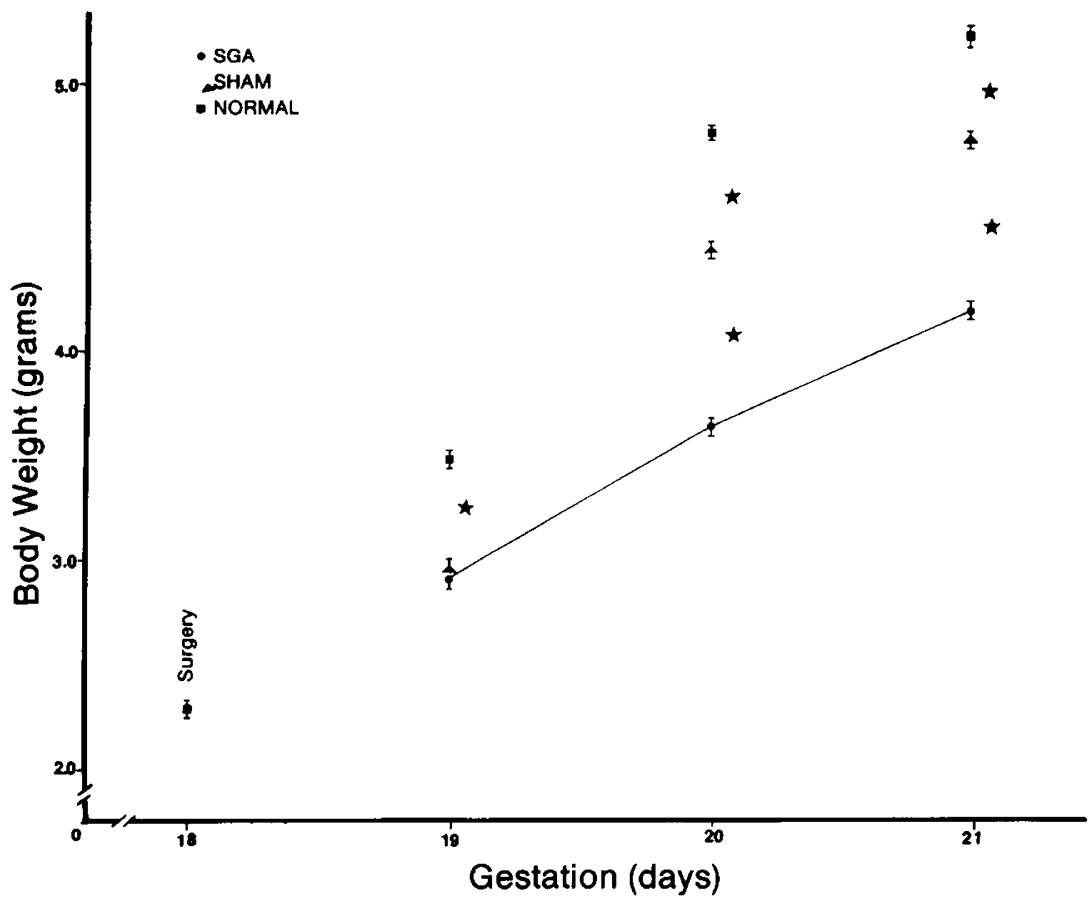

Fig. 1. Sequential body wt measurements. SGA and sham fetuses had equivalent weights $24 \mathrm{~h}$ after maternal uterine artery ligation or sham surgery. These were significantly less than those of normals. On d 20, 21, and at birth, SGA fetuses were the lightest, shams intermediate, and normals the heaviest $(p<0.01)$.

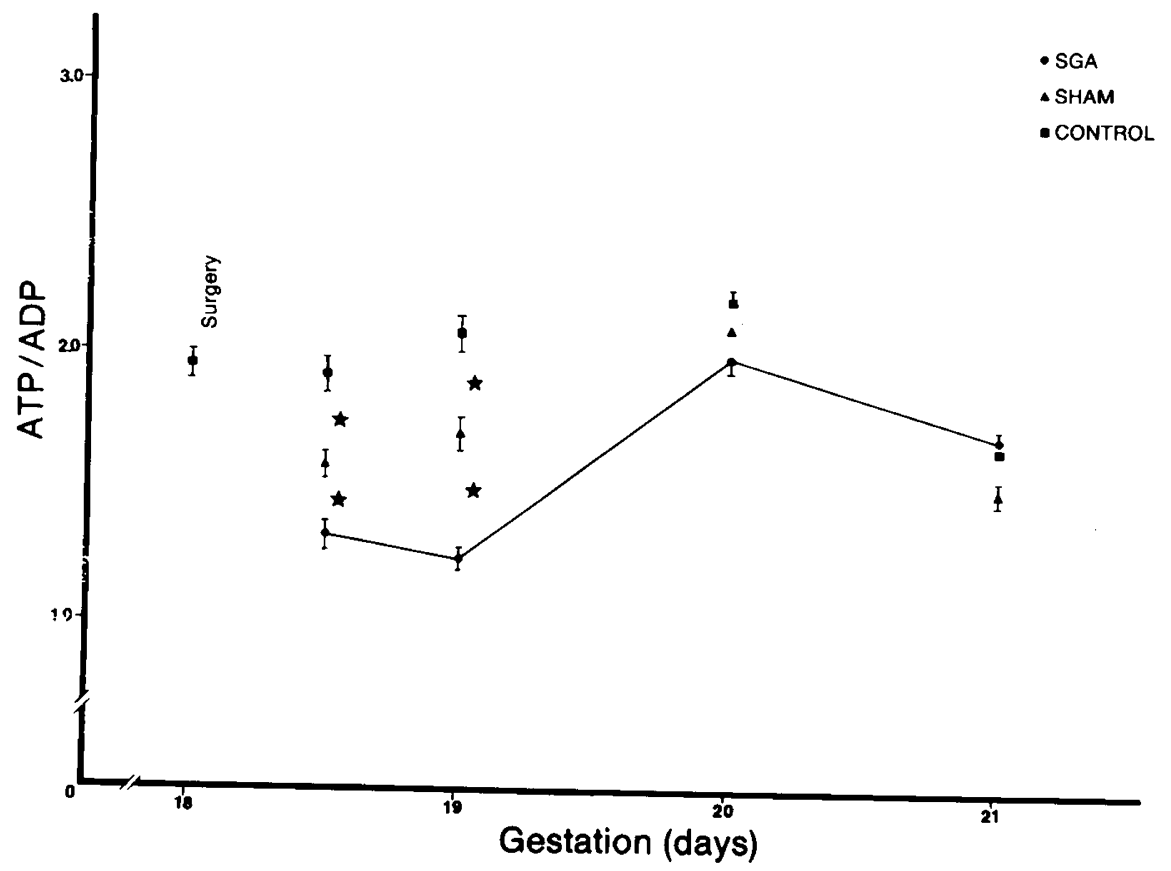

Fig. 2. Fetal hepatic ATP/ADP. At $12 \mathrm{~h}$ after surgery, SGA fetuses had significantly diminished values, whereas shams had intermediate values relative to normals $(p<0.01)$. While this relation remained on $\mathrm{d} 19$, no differences were apparent between group on $\mathrm{d} 20$ and 21 . Adenylate charge ratios demonstrated similar relations.

$(p<0.001)$, and remained so on $\mathrm{d} 19$ (SGA pH $7.11 \pm 0.007$, $\mathrm{PCO}_{2} 86 \pm 7$ torr, $\mathrm{PO}_{2} 19 \pm 5$ torr; sham pH $7.18 \pm 0.006, \mathrm{PCO}_{2}$ $75 \pm 9$ torr, $\mathrm{PO}_{2} 21 \pm 4$ torr; normal pH $7.23 \pm 0.005, \mathrm{PCO}_{2} 56$ \pm 9 torr, $\mathrm{PO}_{2} 27 \pm 5$ torr). On d 20 and 21, sham and normal fetuses had values equivalent to those of normal fetuses. Values for normal fetuses were similar to preceding days.

In the studies in which blood was sampled from fetuses of anesthetized mothers with the placentas attached to the uterus, we determined maternal-fetal glucose relations. Twelve $h$ after surgery and on d 19, SGA fetuses had mean plasma glucose concentrations that were significantly less than sham and normal fetuses. Sham fetuses had intermediate values. Inasmuch as maternal glucose concentrations did not differ between groups (range 150 to $180 \mathrm{mg} / \mathrm{dL}$ ) on any day of gestation, fetal/maternal glucose ratios differed significantly on d 18 and 19 . On d 20 and 21 , there were no differences in fetal plasma glucose concentrations or fetal/maternal relations. Plasma insulin concentrations were significantly diminished in SGA compared to sham and 
Table 1. Concentrations of hepatic adenylate nucleotides ( $\mu \mathrm{mol} / \mathrm{g}$ liver)

\begin{tabular}{|c|c|c|c|c|c|}
\hline & \multicolumn{5}{|c|}{ Gestational age (d) } \\
\hline & \multicolumn{2}{|c|}{18} & \multirow[b]{2}{*}{19} & \multirow[b]{2}{*}{20} & \multirow[b]{2}{*}{21} \\
\hline & Baseline & $12 \mathrm{~h}$ & & & \\
\hline \multicolumn{6}{|l|}{ ATP } \\
\hline SGA & & $1.481 \pm 0.090^{*}$ & $1.300 \pm 0.090^{*}$ & $1.899 \pm 0.091$ & $1.798 \pm 0.070$ \\
\hline Sham & & $1.690 \pm 0.070^{*}$ & $1.599 \pm 0.081^{*}$ & $2.005 \pm 0.099$ & $1.801 \pm 0.090$ \\
\hline Normal & $1.862 \pm 0.049$ & $1.901 \pm 0.078$ & $2.003 \pm 0.090$ & $1.901 \pm 0.085$ & $1.900 \pm 0.078$ \\
\hline \multicolumn{6}{|l|}{ ADP } \\
\hline SGA & & $1.410 \pm 0.059^{*}$ & $1.209 \pm 0.071^{*}$ & $0.854 \pm 0.077$ & $0.996 \pm 0.091$ \\
\hline Sham & & $1.110 \pm 0.070^{*}$ & $0.909 \pm 0.050^{*}$ & $0.926 \pm 0.073$ & $0.956 \pm 0.081$ \\
\hline Normal & $0.964 \pm 0.058$ & $0.860 \pm 0.082$ & $0.799 \pm 0.082$ & $0.901 \pm 0.089$ & $0.899 \pm 0.089$ \\
\hline \multicolumn{6}{|l|}{ AMP } \\
\hline SGA & & $0.900 \pm 0.075$ & $0.834 \pm 0.080^{*}$ & $0.535 \pm 0.095$ & $0.689 \pm 0.099$ \\
\hline Sham & & $0.860 \pm 0.080^{*}$ & $0.682 \pm 0.090$ & $0.421 \pm 0.113$ & $0.558 \pm 0.100$ \\
\hline Normal & $0.566 \pm 0.100$ & $0.500 \pm 0.090$ & $0.589 \pm 0.043$ & $0.434 \pm 0.057$ & $0.534 \pm 0.090$ \\
\hline \multicolumn{6}{|c|}{ Charge ratio } \\
\hline SGA & & $0.537 \pm 0.061$ & $0.497 \pm 0.048^{*}$ & $0.770 \pm 0.100$ & $0.709 \pm 0.092$ \\
\hline Sham & & $0.613 \pm 0.079^{*}$ & $0.653 \pm 0.047^{*}$ & $0.763 \pm 0.068$ & $0.789 \pm 0.099$ \\
\hline Normal & $0.701 \pm 0.041$ & $0.803 \pm 0.041$ & $0.840 \pm 0.073$ & $0.780 \pm 0.103$ & $0.810 \pm 0.083$ \\
\hline
\end{tabular}

* Indicates differences $p<0.05$ to $<0.01$.

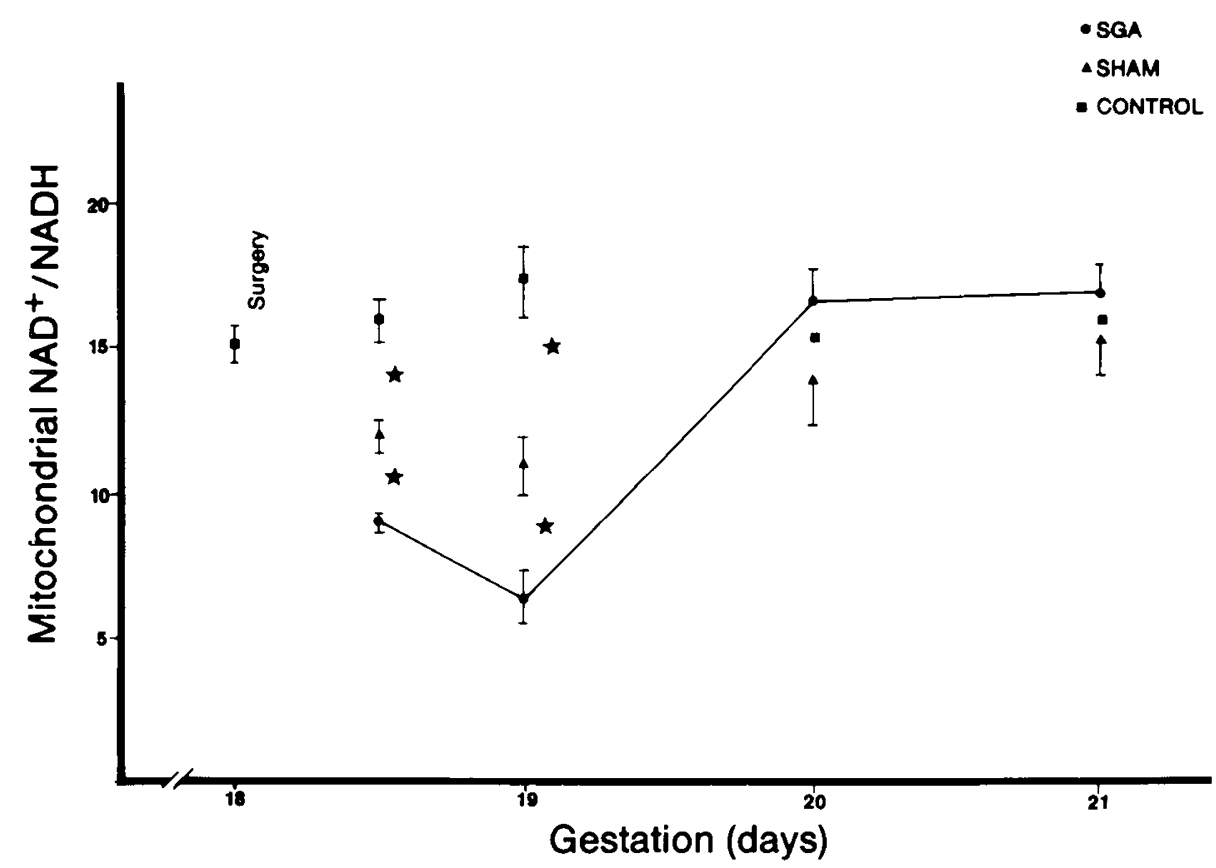

Fig. 3. Fetal hepatic mitochondrial $\mathrm{NAD}^{+} / \mathrm{NADH}$. At $12 \mathrm{~h}$ after ligation, SGA fetuses had significantly diminished values while normals had unchanged values. Shams had intermediate values $(p<0.01)$. These differences were also apparent on d 19; after this, all groups had similar values.

normal fetuses on d 18 to 20 of gestation, whereas plasma glucagon concentrations were significantly elevated from $\mathrm{d} 18$ to 21 (Table 3).

Newborn SGA pups had significantly decreased plasma glucose concentrations at $10 \mathrm{~min}$ of life (SGA $50.0 \pm 3.0$; sham $79.3 \pm 6.1$; normal $81.0 \pm 4.3 \mathrm{mg} / \mathrm{dL}, p<0.001)$ and $240 \mathrm{~min}$ of life (SGA $39.0 \pm 3.1$; sham $52.1 \pm 3.5$; normal $53.5 \pm 2.5$ $\mathrm{mg} / \mathrm{dL}, p<0.001)$. At both points, hepatic ATP/ADP, adenylate charge ratio, and mitochondrial and cytosolic $\mathrm{NAD}^{+} / \mathrm{NADH}$ did not differ between groups. Hepatic ATP/ADP increased in all groups (SGA $1.69 \pm 0.10$ to $2.10 \pm 0.11$; sham $1.59 \pm 0.11$ to $2.20 \pm 0.11$; normal $1.68 \pm 0.11$ to $2.09 \pm 0.10$ ). Cytosolic $\mathrm{NAD}^{+} / \mathrm{NADH}(\mathrm{SGA} 590.2 \pm 89.1$ to $2100.3 \pm 100.1$; sham
$523.6 \pm 98.1$ to $2119.5 \pm 109.3$; normal $560.3 \pm 120.2$ to 2200.3 \pm 120.3 ) and mitochondrial NAD ${ }^{+} / \mathrm{NADH}$ increased (SGA 11.3 \pm 1.2 to $21.0 \pm 3.1$, sham $10.6 \pm 1.5$ to $22.3 \pm 1.3$, normal 10.9 \pm 2.1 to $22.0 \pm 2.5$ ). Arteriovenous blood gas tensions and $\mathrm{pH}$ increased significantly between 10 and $240 \mathrm{~min}$; these variables did not differ between groups.

\section{DISCUSSION}

Our data demonstrate a relation between fetal hypoxia, hypercarbia, acidosis, and limited glucose availability resulting from 
Table 2. Concentrations of hepatic metabolites in fetal rats ( $\mu \mathrm{mol} / \mathrm{g}$ liver)

\begin{tabular}{|c|c|c|c|c|c|}
\hline & \multicolumn{5}{|c|}{ Gestational age (d) } \\
\hline & \multicolumn{2}{|c|}{18} & \multirow[b]{2}{*}{19} & \multirow[b]{2}{*}{20} & \multirow[b]{2}{*}{21} \\
\hline & Baseline & $12 \mathrm{~h}$ & & & \\
\hline \multicolumn{6}{|l|}{ Lactate } \\
\hline SGA & & $4.581 \pm 0.739$ & $4.028 \pm 0.383$ & $4.704 \pm 0.319$ & $4.687 \pm 0.300$ \\
\hline Sham & & $4.498 \pm 0.642$ & $5.050 \pm 0.349$ & $4.740 \pm 0.310$ & $4.744 \pm 0.350$ \\
\hline Normal & $5.060 \pm 0.560$ & $4.884 \pm 0.644$ & $4.910 \pm 0.280$ & $4.890 \pm 0.180$ & $4.611 \pm 0.299$ \\
\hline \multicolumn{6}{|l|}{ Pyruvate } \\
\hline SGA & & $0.223 \pm 0.019^{*}$ & $0.249 \pm 0.040^{*}$ & $0.329 \pm 0.049^{*}$ & $0.359 \pm 0.063$ \\
\hline Sham & & $0.173 \pm 0.019^{*}$ & $0.180 \pm 0.034^{*}$ & $0.173 \pm 0.010$ & $0.309 \pm 0.031$ \\
\hline Normal & $0.159 \pm 0.036$ & $0.130 \pm 0.010$ & $0.129 \pm 0.011$ & $0.164 \pm 0.011$ & $0.307 \pm 0.075$ \\
\hline \multicolumn{6}{|c|}{ Acetoacetate } \\
\hline SGA & & $0.334 \pm 0.030$ & $0.476 \pm 0.091$ & $0.485 \pm 0.046$ & $0.494 \pm 0.032$ \\
\hline Sham & & $0.322 \pm 0.056$ & $0.460 \pm 0.033$ & $0.475 \pm 0.033$ & $0.400 \pm 0.020$ \\
\hline Normal & $0.359 \pm 0.039$ & $0.305 \pm 0.018$ & $0.400 \pm 0.029$ & $0.485 \pm 0.069$ & $0.455 \pm 0.054$ \\
\hline \multicolumn{6}{|l|}{ BOHB } \\
\hline SGA & & $0.735 \pm 0.073^{*}$ & $1.289 \pm 0.090^{*}$ & $0.644 \pm 0.025$ & $0.611 \pm 0.052$ \\
\hline Sham & & $0.560 \pm 0.063^{*}$ & $0.878 \pm 0.084^{*}$ & $0.640 \pm 0.090$ & $0.660 \pm 0.025$ \\
\hline Normal & $0.399 \pm 0.103$ & $0.393 \pm 0.066$ & $0.455 \pm 0.078$ & $0.620 \pm 0.083$ & $0.644 \pm 0.090$ \\
\hline
\end{tabular}

* Indicates differences $p<0.05$ to $<0.01$.

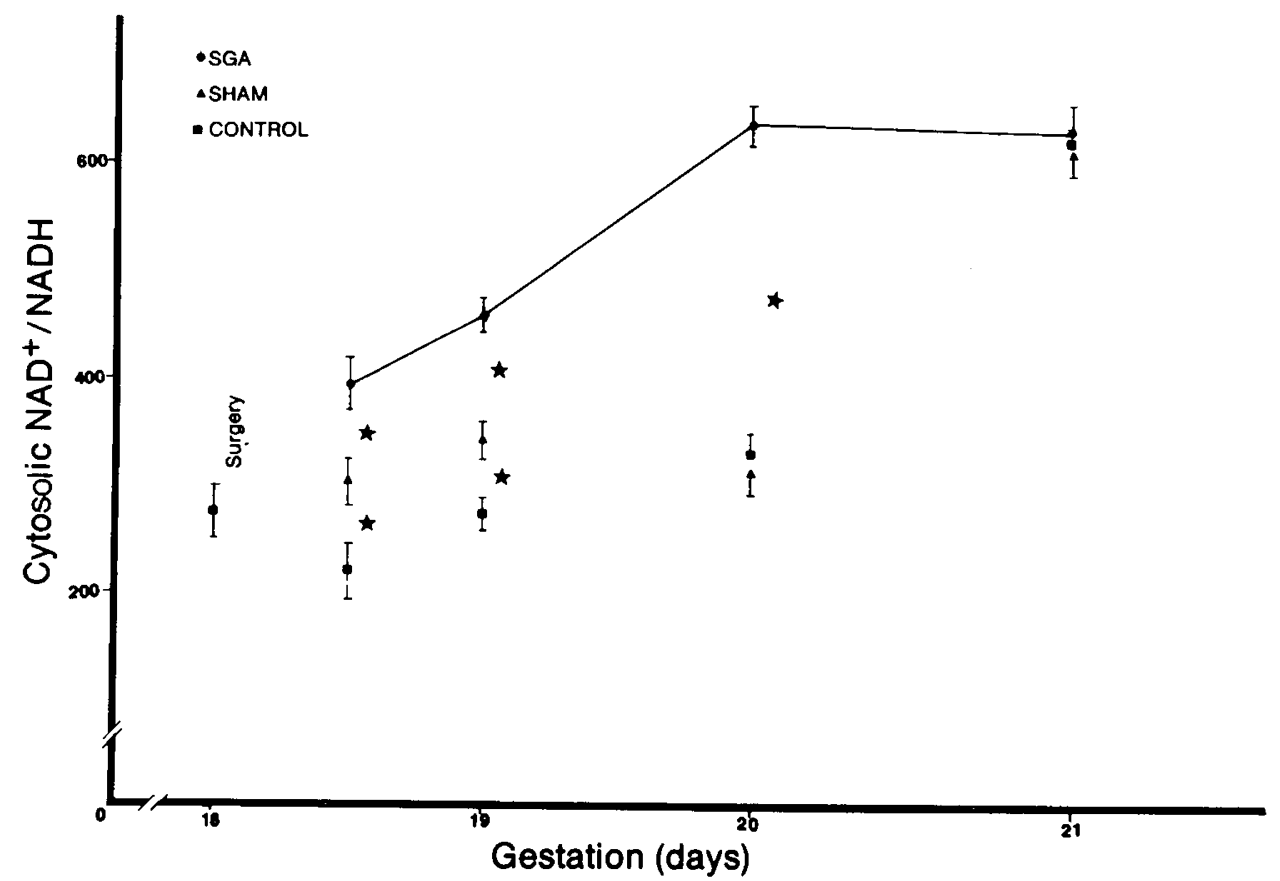

Fig. 4. Fetal hepatic cytosolic NAD ${ }^{+} / \mathrm{NADH}$. Twelve $\mathrm{h}$ after surgery, SGA fetuses had significantly elevated values, while shams had intermediate, and normal fetuses had values that did not differ from d-18 baseline $(p<0.01)$. These relations were also apparent on d 19 . Between $\mathrm{d} 19$ and 20 , SGA fetuses significantly increased cytosolic $\mathrm{NAD}^{+} / \mathrm{NADH}(p<0.01)$, whereas sham and normal fetuses had similar values. Between $\mathrm{d} 20$ and 21 , sham and normal fetuses significantly increased cytosolic NAD ${ }^{+} / \mathrm{NADH}(p<0.01)$ so that their values were equivalent to SGA fetuses.

maternal uterine artery ligation with alterations in hepatic ATP/ $\mathrm{ADP}$, adenylate charge ratio, and mitochondrial $\mathrm{NAD}^{+} / \mathrm{NADH}$. Within $12 \mathrm{~h}$ of maternal anesthesia and surgery, these variables decreased greatly in SGA and to a lesser extent in sham fetuses. Cytosolic $\mathrm{NAD}^{+} / \mathrm{NADH}$ paradoxically increased. Had these variables not returned to a normal range on the latter days of gestation, the fetuses probably would not have survived. The ultimate effect of all of these alterations was to retard fetal growth. These relatively temporary changes in fetal hepatic energy and redox states in combination with hypoxia, hypercarbia, acidosis, limited glucose availability and other factors limited fetal growth.

For $24 \mathrm{~h}$ after maternal surgery, the growth rates of SGA and sham fetuses were diminished equally. Between 19 and 20, the growth of sham fetuses accelerated so that by $\mathrm{d} 20$, the body wt of all three groups differed significantly. Primary among the variables responsible for this altered growth was the decreased provision of maternal glucose and altered gaseous exchange. The limitation of both variables was directly related to the growth retardation of the SGA and sham fetuses. The limited provision of glucose suggested by the static measurements of fetal and maternal glucose concentrations significantly decreased fetal plasma insulin concentrations. Inasmuch as insulin is important for stimulating fetal growth (14), its limitation in combination with limited glucose availability retarded fetal growth. This as- 


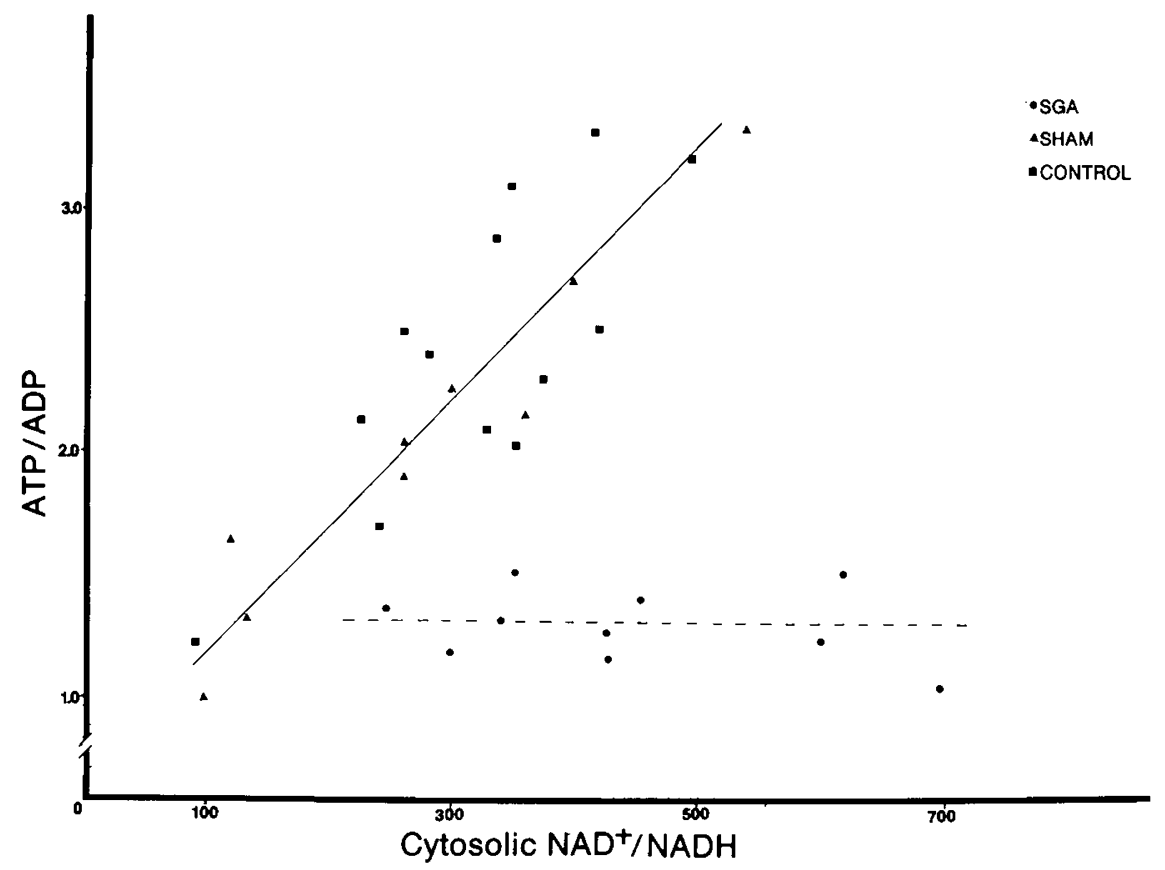

Fig. 5. Relation between fetal hepatic ATP/ADP and cytosolic NAD $/ \mathrm{NADH}$. These variables correlated directly for normal and sham fetuses considered together (solid line, $r=0.779, p<0.01, \mathrm{y}=0.0007 \mathrm{x}+0.009)$. No relation between these variables was apparent in SGA fetuses $($ dashed line).

Table 3. Fetal metabolic variables

\begin{tabular}{|c|c|c|c|c|c|}
\hline & \multicolumn{5}{|c|}{ Gestational age (d) } \\
\hline & \multicolumn{2}{|c|}{18} & \multirow[b]{2}{*}{19} & \multirow[b]{2}{*}{20} & \multirow[b]{2}{*}{21} \\
\hline & Baseline & 12 & & & \\
\hline \multicolumn{6}{|c|}{ Fetal glucose (mg/dL) } \\
\hline SGA & & $30.5 \pm 2.4^{*}$ & $33.5 \pm 4.0^{*}$ & $94.1 \pm 6.7$ & $99.5 \pm 6.0$ \\
\hline Sham & & $40.0 \pm 2.3^{*}$ & $64.9 \pm 6.8^{*}$ & $93.0 \pm 5.5$ & $97.1 \pm 4.9$ \\
\hline Normal & $51.3 \pm 2.7$ & $50.5 \pm 2.7$ & $87.1 \pm 5.1$ & $94.0 \pm 6.6$ & $93.1 \pm 5.1$ \\
\hline \multicolumn{6}{|c|}{ Fetal/maternal glucose } \\
\hline SGA & & $0.23 \pm 0.05^{*}$ & $0.22 \pm 0.02^{*}$ & $0.61 \pm 0.05$ & $0.60 \pm 0.04$ \\
\hline Sham & & $0.30 \pm 0.05^{*}$ & $0.43 \pm 0.05^{*}$ & $0.62 \pm 0.03$ & $0.62 \pm 0.03$ \\
\hline Normal & $0.39 \pm 0.06$ & $0.38 \pm 0.04$ & $0.56 \pm 0.04$ & $0.60 \pm 0.04$ & $0.59 \pm 0.06$ \\
\hline \multicolumn{6}{|c|}{ Fetal glycogen (mg/g liver) } \\
\hline SGA & & $10.4 \pm 3.1^{*}$ & $11.0 \pm 1.8^{*}$ & $18.3 \pm 3.5^{*}$ & $30.1 \pm 4.0$ \\
\hline Sham & & $15.2 \pm 2.9$ & $17.1 \pm 1.1^{*}$ & $36.5 \pm 5.5$ & $53.1 \pm 2.0$ \\
\hline Normal & $10.3 \pm 3.2$ & $14.6 \pm 3.0$ & $25.6 \pm 3.1$ & $35.6 \pm 6.6$ & $51.2 \pm 4.1$ \\
\hline \multicolumn{6}{|c|}{ Fetal insulin $(\mu \mathrm{U} / \mathrm{mL})$} \\
\hline SGA & & $98.3 \pm 16.1^{*}$ & $109.5 \pm 19.5^{*}$ & $130.9 \pm 18.3^{*}$ & $240.7 \pm 30.5$ \\
\hline Sham & & $225.1 \pm 42.3$ & $240.7 \pm 45.4$ & $275.9 \pm 43.4$ & $250.1 \pm 30.3$ \\
\hline Normal & $210.1 \pm 60.1$ & $230.6 \pm 41.4$ & $261.9 \pm 43.3$ & $281.5 \pm 46.6$ & $263.1 \pm 50.1$ \\
\hline \multicolumn{6}{|c|}{ Fetal glucagon $(\mathrm{pg} / \mathrm{mL})$} \\
\hline SGA & & $280.1 \pm 66.7^{*}$ & $460.5 \pm 80.9^{*}$ & $530.1 \pm 73.2^{*}$ & $558.3 \pm 69.1$ \\
\hline Sham & & $200.0 \pm 60.7$ & $220.1 \pm 63.3$ & $400.9 \pm 68.8$ & $410.9 \pm 59.1$ \\
\hline Normal & $180.9 \pm 61.5$ & $190.0 \pm 71.3$ & $228.5 \pm 68.9$ & $390.7 \pm 67.9$ & $399.7 \pm 69.9$ \\
\hline
\end{tabular}

* Indicates differences $p<0.05$ to $<0.01$.

sociation between altered fetal growth and glucose and insulin availability has been reported in a number of species (15-17), and we (4) and others (18) have noted a similar decrease in the availability of this hormone in previous studies of the SGA rat fetus. The extreme limitation of gaseous exchange and glucose availability in SGA fetuses resulted in the most extensive alterations in hepatic energy, mitochondrial, and cytosolic redox states. Since energy and redox states are critical modulators of cellular metabolism, their alteration heightened the effects of limited insulin and glucose availability in retarding growth. The significant although lesser alteration in these variables in sham fetuses affected their growth to a less significant degree.

Maternal ketogenesis could have affected determination of fetal hepatic redox state by this technique as ketones quite readily cross the placenta. We could not directly assess this possibility as our rapid killing technique precluded sampling of maternal blood 
for ketones at the time that fetal livers were obtained. Plasma glucose concentrations did not differ between SGA, sham, and normal maternal rats in studies used for simultaneous maternal/ fetal plasma sampling. No differences were apparent even at 12 $\mathrm{h}$ after surgery. Since glucose availability and ketogenesis are linked, this similarity suggests that ketone production did not differ among SGA, sham, and normal maternal rats. Thus, the conditions under which fetal hepatic redox state were determined were probably similar for all three groups. The fetal hepatic metabolite concentrations and energy and redox states in our study are similar to values reported by others for the fetal rat (5, $11)$ and $\operatorname{dog}(19)$ in which the rapid killing technique was used. This method of fetal sampling is preferable to using anesthesia that can cause maternal hypoventilation (4) and result in artifactual changes in fetal redox and energy states (20).

Another factor that could have contributed to the differences in fetal energy and redox states between groups is hepatic hematopoiesis, a process that can be increased in the SGA fetus. Others have reported that hepatic hematopoiesis does not differ between SGA and normal fetal rats (21), and in previous studies we found that fetal hematocrit does not differ among SGA, sham, and normal fetuses $(2,4)$. These observations and our study did not address the possibility that hematopoietic cell populations might differ between SGA and normal fetuses and that the energy and redox state of each population might be differently altered.

Our studies could not determine the individual effect of decreased gaseous exchange and limited glucose availability on energy and redox states. The static measurements of fetal/maternal glucose ratios suggest that transplacental glucose was limited in the SGA and sham fetuses; others have demonstrated with 2deoxyglucose that maternal uterine artery ligation decreases glucose flux (23). The delineation of the effect of these alterations on energy and redox states is made more difficult by the fact that gaseous exchange and glucose availability returned to normal in SGA and sham fetuses on d 20. Previous studies have not fully characterized this relationship. Fetuses of maternal rats fasted for $96 \mathrm{~h}$ who have limited glucose provision but normal gaseous exchange have decreased hepatic ATP/ADP and adenylate charge ratios but normal redox states (5). However, fasting the pregnant dog significantly increases fetal lactate, AC, and $\mathrm{BOHB}$ concentrations and diminishes both fetal hepatic adenylate charge ratio and redox state $(19,24)$. Fetal rats rendered hypoxic and hypercarbic have both diminished hepatic energy and redox states (20), whereas graded hypoxia in the 2-d-old rat pup decreases hepatic adenylate charge ratio and mitochondrial and cytoplasmic redox states (22). Of note, these changes result from decreases in hepatic ATP and acetoacetate and increases in pyruvate concentrations. Similar changes in these variables were responsible for the altered energy and mitochondrial redox states in our SGA and sham fetuses.

Whereas the relative effects of altered gaseous exchange and limited fuel availability upon redox and energy states cannot be absolutely identified, the effect of uterine artery ligation is extreme. The changes in energy and redox states of our SGA fetuses exceeded by three-fold the changes reported for the 2-d-old pup breathing $0 \%$ oxygen (22). However, the degree of diminution of ATP relative to ADP and AMP suggests that SGA and sham fetuses did not totally revert to anaerobic metabolism. Had this occurred, ADP and AMP should have increased to a greater extent than we observed. A greater reliance on anaerobic metabolism would have resulted in certain fetal death.

The severe changes in energy and redox states in the SGA and sham fetuses profoundly affected their growth, as both demonstrated significantly diminished growth patterns after surgery. This emphasizes the profound effect of maternal uterine artery ligation on fetal growth; it also points out that the maternal anesthesia and uterine manipulation or sham surgery are sufficiently traumatic to alter these cellular states and limit fetal growth.
Two mechanisms could be responsible for the opposite responses of mitochondrial and cytosolic redox states to maternal uterine artery ligation and sham surgery. Under normal circumstances pyruvate enters the mitochondrion and is catalyzed to acetyl $\mathrm{CoA}$ by pyruvate dehydrogenase. Hypoxia inhibits this reaction and causes pyruvate to accumulate in the cytosol thereby increasing cytosolic $\mathrm{NAD}^{+} / \mathrm{NADH}$. In confirmation of this possibility, pyruvate concentrations were significantly increased in SGA and to a lesser extent sham fetuses. Another possible cause of the discordant cytosolic and mitochondrial redox states might have been the limited accumulation and increased breakdown of hepatic glycogen in SGA and sham fetuses. Glycogen deposition was limited in part due to decreased glucose provision. In addition, the elevated plasma glucagon from d 18 to 21 and diminished insulin concentrations from d 18 to 20 limited glycogen accumulation and favored its breakdown. This generated hepatic pyruvate thereby increasing cytosolic $\mathrm{NAD}^{+} / \mathrm{NADH}$.

In adult animals, hepatic ATP/ADP and adenylate charge ratios generally correlate directly with cytosolic NAD ${ }^{+} / \mathrm{NADH}$ as a result of the equilibrium relation between cytosolic adenine and nicotinamide nucleotides (25). These relations were intact for our normal and sham fetuses. The lack of correlation in SGA fetuses probably resulted from the extreme alterations in gaseous exchange that decreased hepatic ATP and increased pyruvate concentrations.

Newborn SGA pups had significantly diminished glucose concentrations at 10 and $240 \mathrm{~min}$ of life. The fact that hepatic energy and redox states increased equivalently in all three groups suggests that these variables were not responsible for the hypoglycemia in SGA newborns. The values for these variables are similar to those reported by others for normal rat pups (26-28). The limited hepatic glycogen concentrations in SGA pups directly contributed to the hypoglycemia. In previous studies we found that the induction of hepatic phosphoenolpyruvate carboxykinase, a key gluconeogenic enzyme, is delayed up to 240 min in the newborn SGA rat pup (6) and is another major factor for the development of hypoglycemia. Thus, while considerable alterations of hepatic energy and redox states occur in utero, these are normal by term and do not contribute to the development of hypoglycemia.

These studies indicate that the alterations in several physiologic variables resulting from uterine artery ligation or anesthesia alone affect hepatic energy and redox state. Our studies suggest that the extent of change of these vital metabolic functions is related to the degree of perturbation of gaseous exchange, $\mathrm{pH}$, and glucose availability. Changes in all of these variables were important for retarding fetal growth.

\section{REFERENCES}

1. Gruenwald P 1963 Chronic fetal distress and placental insufficiency. Biol Neonate 5:215-223

2. Ogata ES, Bussey M, LaBarbera A, Finley S 1985 Altered growth, hypoglycemia, hypoalaninemia, and ketonemia in the young rat. Postnatal consequences of intrauterine growth retardation. Pediatr Res 19:32-37

3. Barr M, Jensch R, Brent R 1970 Prenatal growth in the albino rat: effects of number, intrauterine position, and resorptions. Am J Anat 128:413-428

4. Ogata ES, Bussey M, Finley S 1986 Altered gas exchange, limited glucose and branched chain amino acids, and hypoinsulinism retard fetal growth in the rat. Metabolism 35:970-977

5. Girard JR, Ferre P, Gilbert M, Kervran A, Assan R, Mark EB 1977 Fetal metabolic response to maternal fasting in the rat. Am J Physiol 232:E456462

6. Bussey M, Finley S, LaBarbera A, Ogata ES 1985 Hypoglycemia in the newborn growth-retarded rat: delayed phosphoenolpyruvate carboxykinase induction despite increased glucagon availability. Pediatr Res 19:363-367

7. Gutmann I, Wahlefeld A 1978 Lactate: determinations with lactate dehydrogenase and NAD. In: Bergmeyer HU (ed) Methods of Enzymatic Analysis. New York, pp 1464-1468

8. Mellanby J, Williamson DH 1978 Acetoacetate. In: Bergmeyer HU (ed) Methods of Enzymatic Analysis. New York, pp 1840-1844

9. Williamson DH, Mellanby J, Krebs H 1962 Enzymatic determination of $\mathrm{D}(-)$-B-hydroxybutyric acid and acetoacetic acid in blood. Biochem J 82:9097

10. Gruber W, Mollering $\mathrm{H}$, Bergmeyer HU 1978 Determination of ADP, ATP, 
and sum of GTP and ITP in biological material. In: Bergmeyer HU (ed) Methods of Enzymatic Analysis. New York, pp 2078-2081

11. Williamson DH, Lund P, Krebs HA 1967 The redox state of free nicotinamideadenine dinucleotide in the cytoplasm and mitochondria of rat liver. Biochem J 103:514-527

12. Ballard FJ 1970 Adenine nucleotides and the adenylate kinase equilibrium in livers of foetal and newborn rats. Biochem J 117:231-238

13. Snedecor GW, Cochran WB 1972 Statistical Methods. Iowa University Press, Ames, IA

14. Hill DJ, Milner RDG 1985 Insulin as a growth factor. Pediatr Res 19:879-886

15. Freinkel N 1980 Of pregnancy and progeny. Diabetes 29:1023-1035

16. Fletcher JM, Falconer J, Bassett JM 1982 The relationship of body and placental weight to plasma levels of insulin and other hormones during development in fetal rabbits. Diabetologia 23:124-130

17. Girard JR, Kervran A, Soufflet E, Assan R 1974 Factors affecting the secretion of insulin and glucagon by the rat fetus. Diabetes 23:310-316

18. Girard JR, Chanez C, Kervran A, Tordet-Caridroit C, Assan R 1976 Studies on experimental hypotrophy in the rat. III. Plasma insulin and glucagon. Biol Neonate 29:262-266

19. Miettien EL 1981 Effect of maternal canine starvation on fetal and neonatal liver metabolism. Am J Physiol 240:E88-E94

20. Ballard FJ 1971 The development of gluconeogenesis in rat liver. Biochem J
122:265-274

21. Larroche J, Herissard N, Bennoun M 1971 Hepatic hematopoiesis in hypotrophic rats. Biol Neonate 15:279-289

22. Ballard FJ 1971 Regulation of gluconeogenesis during exposure of young rats to hypoxic conditions. Biochem J 121:169-178

23. Nitzan M, Orloff S, Schulman J 1979 Placental transfer of analogues of glucose and amino acids in experimental intrauterine growth retardation. Pediatr Res 13:100-103

24. Kliegman RM, Miettien EL, Adam PAJ 1981 Fetal and neonatal responses to maternal canine starvation: circulating fuels and neonatal glucose production. Pediatr Res 15:945-951

25. Veech RL, Raijman L, Krebbs H 1970 Equilibrium relations between the cytoplasmic adenine nucleotide and nicotinamide-adenine nucleotide system in rat liver. Biochem $\mathrm{J}$ 1 17:499-503

26. Ferre P, Pegorier JP, Williamson DH, Girard J 1979 Interactions in vivo between oxidation of nonesterified fatty acids and gluconeogenesis in the newborn rat. Biochem J 182:593-598

27. Cuezva J, Chitra C, Patel MS 1982 The newborn of diabetic rat. II. Impaired gluconeogenesis in the postnatal period. Pediatr Res 638-643

28. Cuezva J, Fernandez E, Valcarce C, Medina JM 1983 The role of ATP/ADP ratio in the control of hepatic gluconeogenesis during the early neonatal period. Biochem Biophys Acta 759:292-295 